\title{
GERAÇÃO E DESTINO DOS RESÍDUOS ELETRÔNICOS DE INFORMÁTICA NAS INSTITUIÇÕES DE ENSINO SUPERIOR DE NATAL-RN
}

\author{
Ricardo Teixeira Gregório de Andrade \\ Tecnólogo em Gestão Ambiental - IFRN. Mestrando em Engenharia de Produção - UFRN, \\ Linha de Gestão Ambiental. Email: rtnatal@gmail.com \\ Carlos Sigmund Meneses Fonseca \\ Engenheiro da Computação - UNP. Email: carlos.sigmund@gmail.com \\ Karen Maria da Costa Mattos \\ Engenheira Agrônoma - UFScar. Dra em Agronomia (Irrigação e Drenagem) - UNESP \\ Email: karenmattos@yahoo.com.br
}

\section{RESUMO}

Os produtos eletrônicos, hodiernamente tão imiscuídos em nosso cotidiano e cultura, e confeccionados para nos trazerem comodidade e conforto, são responsáveis por gerar severos prejuízos (econômicos, sociais, ambientais), desde a produção ao descarte, a despeito de sua aparente inofensibilidade. A expansividade do uso de equipamentos e as constantes trocas de versões, motivados pela febre de consumo imposta e obsolescência programada, geram um montante de resíduos colossal e praticamente imensurável. A destinação final incorreta destes materiais, os resíduos eletroeletrônicos (ou chamados 'lixo digital'), pode em pouco tempo se agravar em grandes desastres ambientais, caso não sejam tomadas as providências necessárias. Na cidade de Natal, em similaridade ao contexto nacional, não existe ainda uma política de tratamento do lixo digital. O presente estudo objetiva traçar um breve e inicial panorama da geração e destinação dos resíduos eletrônicos de informática de algumas das principais instituições de ensino superior de Natal-RN. Os dados levantados, através de entrevistas e bancos de dados institucionais, evidenciam a parca consciência quanto ao lixo digital e quão incipiente ainda é a gestão desses resíduos, apesar de serem as instituições de ensino superior os grandes pólos geradores e distribuidores de conhecimentos científicos que possam criar/aplicar as soluções devidas à fiel execução sustentável dos processos produtivos.

PALAVRAS-CHAVE: Resíduos eletroeletrônicos; Lixo digital; Impacto ambiental; Instituições de ensino superior.

\section{GENERATION AND DESTINATION OS INFORMATICA ELETRONIC RESIDUES OF UNIVERSITIES IN NATAL-RN, BRAZIL}

\begin{abstract}
The electronic products, nowadays so immersed on our culture and daily life, and made to bring us comfort and easiness, are responsible for generating severe prejudices (economical, social and environmental), since production to discard, in spite of their apparently innocuousness. The expansiveness of their use and constants change for new versions, motivated by imposed consumption fever and programmed obsolescence, beget
\end{abstract}


an almost immeasurable amount of electronic residues. The incorrect final destination of those materials, the 'digital trash', may cause great environmental disasters on short time, if the correct providences are not taken. At the city of Natal, similarly to national context, there is no digital trash treatment policy established yet. This study pretends to expose a brief and initial scenery of the generation and destination of the informatics electronic residues of some of most important institutions of superior education of Natal-RN, Brazil. The data raised, through interviews and institutional data bank, demonstrate how scanty and incipient the consciousness about the digital trash still is, despite being those institutions the great generation and distribution poles of scientific knowledge which should create and put into practice the sustainable solutions to the environmental issues.

KEY-WORDS: Electronic residues; Digital trash; Environmental impact; Superior education institutions. 


\section{GERAÇÃO E DESTINO DOS RESÍDUOS ELETRÔNICOS DE INFORMÁTICA NAS INSTITUIÇÕES DE ENSINO SUPERIOR DE NATAL-RN}

\section{INTRODUÇÃO}

Desde o início da história da humanidade, os processos produtivos e seu desenvolvimento vêm sendo motivados pela busca e consecução da eficiência. Porém, essa eficiência, longe da eficácia real, em sua maioria das vezes foi, e ainda é, vislumbrada somente sob o ângulo econômico, em persecução às facilidades imediatas do viver. As demais dimensões (social, ambiental e outras) começaram a ser percebidas como de responsabilidade dos sistemas produtivos somente mais recentemente.

Sob o enfoque econômico e pretensão de facilitar o cotidiano humano, os produtos tecnológicos vêm sofrendo, desde a I Revolução Industrial, uma expansão exponencial em quantidade. Os produtos eletrônicos, como computadores e celulares, permeiam a sociedade de tal forma que grande parte chega a constatar que a sociedade moderna teria sérias dificuldades em se manter sem o concurso deles. Tal amplitude de produção e uso torna necessário um aprofundamento no estudo desta temática, devendo-se perquirir as diversas dimensões da questão.

Os produtos eletrônicos, que, à primeira vista, são equipamentos inofensivos, de uso normal e confeccionados para nos trazerem comodidade e conforto, geram também graves danos (econômicos, sociais, ambientais) desde a produção ao descarte. A expansividade do uso de equipamentos e as constantes trocas de versões, motivados pela febre de consumo imposta e obsolescência programada, geram um montante de resíduos colossal e praticamente imensurável. Quanto à destinação final destes materiais, os resíduos eletroeletrônicos, ou chamados 'lixo digital', podem em pouco tempo se agravar em grandes desastres ambientais, caso não sejam tomadas as providências necessárias.

Na Cidade de Natal, em similaridade ao contexto nacional, não existe ainda uma política de tratamento do Lixo Digital. Com o aumento do poder aquisitivo é cada vez maior o numero de residências com computadores, notebooks, celulares. O planejamento e execução de programas de gestão destes resíduos, na forma de investimentos em indústrias de coleta, reciclagem e conscientização, podem permitir o solucionamento dos problemas. Os subprodutos gerados na produção dos equipamentos eletrônicos poderiam (e deveriam) ser novamente incorporados ao ciclo produtivo, minorando custos (econômicos, sociais, ambientais), além de tempo de produção. As reciclagens térmicas ou materiais destes equipamentos já ofereceriam significativa contribuição, por diminuir a necessidade pela extração de materiais virgens e danos decorrentes deste processo, já que dos componentes de computadores, por exemplo, podem ser reciclados, de acordo com estudo do Departamento de Química Analítica da Universidade Federal do Rio de Janeiro - UFRJ.

Os estudos técnicos e de gestão das propostas supracitadas encontram maior possibilidade de viabilização justamente no âmbito acadêmico universitário, responsável pela produção, ensino e distribuição à população do conhecimento. As universidades devem ser por ideal os grandes centros de aplicação prática dos conhecimentos científicos gerados. 
O presente estudo objetiva traçar um breve e inicial panorama da geração e destinação dos resíduos eletrônicos de informática das três instituições de ensino superior de Natal-RN. Para isso, foram levantados, através de entrevistas e bancos de dados institucionais, as informações referentes de três instituições de ensino superior de Natal, sendo estas duas Universidades (uma federal e outra particular) e uma Faculdade particular.

\section{CONTEXTUALIZAÇÃO}

O montante de lixo digital produzido atualmente pela humanidade está adquirindo proporções preocupantes. Segundo a Organização Não Governamental GreenPeace (2009), $5 \%$ de todo os resíduos digital gerados globalmente são destinados incorretamente ao lixo. O lixo digital encontra-se entre as categorias de resíduo que mais cresce, devendo atingir a marca de 40 milhões de toneladas anuais em breve (DOYLE, 2009). Estima-se que a produção média de um cidadão europeu seja de $14 \mathrm{~kg}$ anuais de lixo eletrônico (DEUTSCHE WELLE BRASIL, 2009). Estrada (2009) expõe a estimativa de que somente $11 \%$ do resíduo eletrônico mundial são destinados a algum tipo de reciclagem.

No Brasil, estima-se a produção de 2,6Kg de lixo eletrônico por habitante. Segundo a Fundação Getúlio Vargas - FGV as vendas de computadores registradas atingiram as marcas de 7,4 e 10,5 milhões para os anos de 2006 e 2007, respectivamente e ultrapassaram os 50 milhões em 2008 (MEIRELLES, 2008). Parte desse crescimento deveu-se à Lei do Bem, que reduziu a carga tributária para o financiamento de computadores e notebooks. Até 2012 avalia-se que este valor chegue a 100 milhões de unidades.

Antunes (2009) coloca que quanto aos aparelhos celulares, a Agência Nacional de Telecomunicações - ANATEL calcula que em 2007 o país possuía 120,98 milhões de assinantes e que até o fim de 2009 deve-se chegar aos 170 milhões. Estes números indicam a enorme pressão no sentido da geração de resíduos, visto que o tempo de vida médio de um computador está estimado em 3 a 4 anos e o de um celular em 1 a 1,5 ano. O grande volume consumido destes produtos, e logo descartados em vista da massiva inovação tecnológica e rápida obsolescência programada, representa graves prejuízos para empresas, sociedade e meio-ambiente.

Economicamente, os prejuízos do descarte destes resíduos, sem reaproveitamento ou reciclagem, decorrem da necessidade de extração de novas matérias-primas (minerais principalmente) e custos envolvidos em toda a cadeia de extração, transporte, beneficiamento, etc. Tais atividades estão cada vez mais custosas devido à intensa e desenfreada exploração dos recursos, o que demanda desenvolvimento de novas tecnologias e busca em locais mais distantes e menos acessíveis. O Índio (subproduto da mineração do zinco), por exemplo, está presente em mais de 1 bilhão de equipamentos fabricados todos os anos, sendo fundamental à fabricação dos monitores LCD e telefones celulares. De acordo com Leite (2009, p.4), as reservas de zinco estão cada vez mais limitadas e, de 2004 até hoje, o preço do Índio aumentou tanto que este se encontra mais caro do que a prata. O autor menciona que "já se realizam reciclagens do metal Índio na 
Bélgica, Japão e EUA, sendo que o Japão consegue retirar metade de suas necessidades anuais do elemento com a reciclagem”. Além dessa perspectiva de custos, o volume de lixo digital redunda em dispêndio de recursos ao ocupar indevidamente lixões e aterros sanitários, exaurindo a vida útil dos depósitos e do sistema de gestão de resíduos sólidos antes do tempo programado - requerendo gastos extras.

Socialmente, o maior dano é sentido pelos trabalhadores que manuseiam diretamente os resíduos sem as condições necessárias (usos de equipamentos de proteção individuais e coletivos), seja informalmente (e.g. sucateiros), no 'mercado cinza' ou os trabalhadores que recebem em suas cidades o lixo digital exportado dos países desenvolvidos, sob discurso de uma pretensa inclusão digital (e.g. trabalhadores asiáticos). Sommer (2009) relata que estimativas de especialistas industriais apontam para percentuais de $50 \%$ a $80 \%$ do lixo eletrônico coletado para reciclagem que são exportados para a Ásia, "onde seus componentes tóxicos vão parar em correntes sangüíneas e cursos de água”. Segundo os estudos da Basel Action Network -BAN (2009), oito em cada dez computadores dos EUA finda em países como a Índia, China e, mais recentemente, países africanos, onde os custos de 'reciclagem' são baixos.

Ambientalmente, os prejuízos são inúmeros, sendo originados concomitantemente aos danos econômicos e sociais. Indiretamente, o processo produtivo dos equipamentos eletrônicos (extração, transporte, produção) tem por consequência o gasto de recursos (materiais e energéticos), queima de combustíveis fósseis e emissões de poluentes sólidos, líquidos e gasosos (inclusos Gases Efeito Estufa - GEE). Consoante estudo da Universidade das Nações Unidas, cerca de 1,8 toneladas de diversos materiais são utilizados no processo produtivo de fabricação de um computador. Os recursos incluem 240 quilos de combustíveis fósseis (aproximadamente 100 vezes seu próprio peso), 22 quilos de produtos químicos e 1.500 quilos de água, a qual deve ser rigorosamente pura e, obviamente, sai contaminada do processo (LEITE, 2009, p.4).

Diretamente, os materiais tóxicos e metais pesados - emitidos ao longo do processo produtivo e descarte indevido dos equipamentos eletrônicos, a exemplo de um computador (Tabela 1) - causam extensivos distúrbios a saúde biótica de ecossistemas e seres vivos. Lixões, aterros controlados e aterros sanitários não são os locais adequados para a destinação final das substâncias contidas nos resíduos sólidos. Muito desse material, quando em contato com a água, é carregado junto com o chorume e contamina o solo, águas superficiais e lençóis subterrâneos e o ar, quando queimado (CELERE et al., 2007).

\section{Tabela 1 - Metais pesados em um computador, percentual de integração e reciclabilidade; Fonte: MCC (2007)}




\begin{tabular}{c|ccc}
\hline Metal & Parte do computador onde é encontrado & $\begin{array}{c}\text { Porcentagem no } \\
\text { computador }\end{array}$ & $\begin{array}{c}\text { Porcentagem } \\
\text { reciclável }\end{array}$ \\
\hline Alumínio & Estrutura, conexões & $14,1723 \%$ & $80,0000 \%$ \\
Bário & Válvula eletrônica & $0,0315 \%$ & $0,0000 \%$ \\
Berílio & Condutivo térmico, conectores & $0,0157 \%$ & $0,0000 \%$ \\
Cádmio & Bateria, chip, semicondutor, estabilizadores & $0,0094 \%$ & $0,0000 \%$ \\
Chumbo & Circuito integrado, soldas, bateria & $6,2988 \%$ & $5,0000 \%$ \\
Cobalto & Estrutura & $0,0157 \%$ & $85,0000 \%$ \\
Cobre & Condutivo & $6,9287 \%$ & $90,0000 \%$ \\
Cromo & Decoração, proteção contra corrosão & $0,0063 \%$ & $0,0000 \%$ \\
Estanho & Circuito integrado & $1,0078 \%$ & $70,0000 \%$ \\
Ferro & Estruturas. encaixe & $20,4712 \%$ & $80,0000 \%$ \\
Gálio & Semicondutor & $0,0013 \%$ & $0,0000 \%$ \\
Germânio & Semicondutor & $0,0016 \%$ & $60,0000 \%$ \\
Índio & Transistor, retificador & $0,0016 \%$ & $60,0000 \%$ \\
Manganês & Estrutura, encaixes & $0,0315 \%$ & $0,0000 \%$ \\
Mercúrio & Bateria, ligamentos, termostatos, sensores & $0,0022 \%$ & $0,0000 \%$ \\
Níquel & Estrutura, encaixes & $0,8503 \%$ & $80,0000 \%$ \\
Ouro & Conexão, condutivo & $0,0016 \%$ & $99,0000 \%$ \\
Prata & Condutivo & $0,0189 \%$ & $98,0000 \%$ \\
Sílica & Vidro & $24,8803 \%$ & $0,0000 \%$ \\
Tântalo & Condensador & $0,0157 \%$ & $0,0000 \%$ \\
Titânio & Pigmentos & $0,0157 \%$ & $0,0000 \%$ \\
Vanádio & Emissor de fósforo vermelho & $0,0002 \%$ & $0,0000 \%$ \\
Zinco & Bateria & $2,2046 \%$ & $60,0000 \%$ \\
Minco & & &
\end{tabular}

Nos seres humanos, os efeitos deletérios decorrentes da presença de metais pesados no organismo são vastos e severos. A seriedade do dano ainda pode se agravar em vista da bioacumulação destes metais (concentração dos compostos nos tecidos em níveis milhares de vezes maiores que os presentes no meio ambiente), que atinge todos os níveis tróficos da cadeia alimentar e pode gerar a cronicidade dos danos sofridos. Os prejuízos relatados culminam na geração de novos gastos econômicos e sociais, pelas necessidades de tratamento de recursos hídricos, de solo e hospitalar. Os problemas se agravam em avalanche e pressionam ações de Responsabilidade Socioambiental Empresarial e governamental.

A primeira atitude global de responsabilidade pela temática se deu em 1989, na Convenção de Basiléia, a qual culminou em tratado internacional com 166 países signatários objetivando a minimização da geração de resíduos perigosos, através do monitoramento dos impactos ambientais das operações de depósito, recuperação e reciclagem, modificações nos próprios processos produtivos e a redução do movimento transfronteiriço desses resíduos. O tratado também estabeleceu necessidade de consentimento prévio, por escrito, por parte dos países importadores e a correta administração ambiental dos depósitos de resíduos. Entretanto, a exportação dos resíduos eletroeletrônicos aos países não membros da 'Organização para a Cooperação e Desenvolvimento Econômico' OECD (sob a emenda da Convenção de Basiléia) ocorreu, grande parte, ilegalmente, devido ao abuso por parte dos exportadores, que misturam aos equipamentos outros sem condições de uso (SILVA, 2007, p.4).

Em 1994, na $2^{\text {a }}$ Reunião das Partes da Convenção de Basiléia, foi aprovado um novo consenso, chamado Basel Ban, proibindo a movimentação transfronteiriça de resíduos perigosos procedentes de países membros da OCDE para países não membros. Porém, esta decisão foi, e ainda é, questionada por países como EUA e Canadá, que assinaram a convenção, mas não ratificaram o consenso, se isentando das responsabilidades previstas 
nele. Fruto deste contexto, a organização internacional Basel Action Network - BAN atua ativamente, se responsabilizando pela fiscalização do fluxo de lixo tóxico no mundo e promovendo intensos estudos técnicos de diagnóstico e alternativas ao solucionamento do problema (BAN, 2009).

Desde então, alguns exemplos de avanço positivo na temática podem ser citados. Em 2003, a União Européia elaborou a lei Diretiva para Lixo Elétrico e Equipamentos Eletrônicos' (Waste Electrical and Electronic Equipment Directive - WEEE), que determina aos fabricantes de equipamentos eletroeletrônicos metas de coleta e reciclagem dos produtos. Em 2006, foi implementada diretriz Restriction on the use of Hazardous Substances RoHS, de 2006, que objetiva evitar ou, ao menos, diminuir o volume de produtos tóxicos e metais pesados que ingressam na União Européia (ENVIRONMENT AGENCY, 2009). Em 2007, foi iniciado o programa StEP (Solving the e-Waste Problem), que congrega a ONU, governos, ONGs e empresas no objetivo de padronizar os processos de reciclagem do lixo digital, aumentar o ciclo de vida dos produtos e harmonizar a legislação e as políticas mundiais que tratam do tema. O programa envolve ainda a construção de guias e diretrizes pertinentes ao trato da questão e a capacitação de países em desenvolvimento. Como fruto do programa, na América do Norte, líderes e gestores empresariais cunharam a e-Stewards, que certifica empresas defensoras e praticantes dos mais elevados padrões de responsabilidade ambiental e social. Os critérios incluem todo tipo de resíduos despejados em aterros, incinerados, ou exportados para os países em desenvolvimento (STEP, 2009).

No Brasil, ainda não existe uma legislação clara que defina a responsabilidade pela reciclagem ou destino sustentável dos resíduos eletrônicos produzidos. Houve, em 1991, a proposição de um projeto-lei (203/91) visando instituir a Política Nacional de Resíduos Sólidos. Ainda em tramitação, o projeto-lei foi enviado ao Congresso Nacional em setembro de 2007 pelo presidente Lula. Em seu capítulo IV, a Política trata da 'logística reversa’, prevendo a criação, por fabricantes, importadores ou comerciantes, de condições para o retorno dos equipamentos pelo consumidor, para reutilização ou reciclagem. Este ponto gera polêmica, pois as indústrias temem que seus custos sejam onerados demasiadamente. Além disso, a devolução do lixo eletrônico depende do consumidor, nem sempre comprometido com o descarte correto (CARVALHO, 2008; PORTAL, 2009). Vigorando acerca da questão, existe, no momento, apenas a Resolução 257 do Conselho Nacional do Meio Ambiente - CONAMA, a qual contempla um tópico, estabelecendo que pilhas e baterias, que possuam em suas composições chumbo, cádmio, mercúrio e seus compostos sejam submetidas aos procedimentos de reutilização, reciclagem, tratamento ou disposição final ambientalmente adequados (BRASIL, 1999).

Assim, dado o pressuposto cultural perdulário em que vivemos e consequentes escassez de políticas e planos de gestão e baixo nível informacional, a consciência e atitudes acerca deste tema são ainda bastante incipientes, por parte tanto da população quanto dos governantes. Uma recente pesquisa feita na cidade de Natal através de questionários expõe que $36 \%$ dos entrevistados possuem total desconhecimento quanto à problemática do lixo eletrônico. Dentre os $64 \%$ informados em algum grau sobre o assunto, a parcela significativa de $83 \%$ não conhece nenhum ponto de coleta de lixo na cidade. Face a isto, $58 \%$ afirmaram ter em casa um eletro-eletrônico sem uso apenas esperando um destino adequado. Quanto ao destino do lixo digital, do total de entrevistados, 36\% vêem a doação 
como melhor opção, 34\% retêm os resíduos em casa e $29 \%$ o destina ao lixo comum (ADRIANO SILVA, 2009).

Não obstante à parca legislação referente e inexistentes programas governamentais de gestão, existem algumas iniciativas por parte de empresas privadas atuantes no país, a exemplo da ItauTec, San Lien e Sir Company (LEITE, 2009). Felizmente, há também o enobrecedor exemplo da Universidade de São Paulo - USP, com execução do projeto 'Criação de Cadeia de Transformação de Lixo Eletrônico', cujo delineamento apresentado a seguir tem por base o estudo de Carvalho (2008).

\section{A USP E O PROJETO 'CRIAÇÃO DE CADEIA DE TRANSFORMAÇÃO DE LIXO ELETRÔNICO'}

O Anuário Estatístico de 2007 da USP revelou que a Universidade possuía cerca de 37.923 microcomputadores, 15.702 impressoras e 4.569 equipamentos de rede, os quais têm ciclo de vida variando de 3 a 4 anos (visto que após este período, estes bens são considerados obsoletos devido ao avanço tecnológico e à demanda de recursos computacionais mais sofisticados para atender requisitos de aplicações mais avançadas). Na prática, estima-se que anualmente $10 \%$ do parque computacional se tornam obsoletos. Desta feita, a Universidade encontrou alguns dilemas referentes ao fim sustentável, diminuição ou eliminação desse lixo digital e garantias do correto destino no caso de doações para instituições e ONGs.

Sob a ética de serem as Universidades o exemplo da aplicação prática da ciência desenvolvida; e face ao crescente volume de lixo digital gerado e, ainda, inexistência de políticas internas ou tampouco em nível de governos estadual e federal, a USP elaborou o projeto ‘Criação de Cadeia de Transformação de Lixo Eletrônico', através de seu Centro de Computação Eletrônica - CCE-USP. O objetivo do projeto é garantir o fim sustentável do lixo digital, através de sua reutilização ou reciclagem.

O projeto é composto de três fases. A primeira consiste na coleta e classificação (e separação) detalhada dos Resíduos Eletro-Eletrônicos - em 2007, o peso total foi de $5.208,7 \mathrm{~kg}$ de lixo eletrônico. Na segunda fase, é realizada uma busca e identificação de empresas parceiras de reciclagem e das empresas fornecedoras de equipamentos eletroeletrônicos verdes. Estas últimas devem seguir a diretriz européia RoHS (devendo todos os componentes dos produtos serem recicláveis) e serem certificadas com as normas ISO 9001 e ISO 14001. A terceira fase constituiu-se na criação do Centro de Descarte e Reciclagem de Lixo Eletrônico - CEDR, o qual promove a gestão destes resíduos e pesquisas/estudos práticos para aprimoramento desta gestão.

O projeto vem rendendo bons resultados, como, por exemplo, a criação de um Selo-verde, uma iniciativa pioneira que consiste na atribuição de um selo a todo equipamento de informática e telecomunicações verde que for adquirido pela USP. O objetivo principal é o real comprometimento da Universidade com a minimização dos prejuízos ambientais gerados por tais produtos e diminuição da geração de lixo eletrônico. Por meio do selo verde, tenciona-se criar um ciclo virtuoso de fornecimento ao serviço público, pela seleção 
de fornecedores com responsabilidade social e ambiental. Na prática. indicadores do percentual esverdeado e verde do parque de TI da USP poderão servir a órgãos públicos na contemplação, em editais, de características técnicas que possam ser classificadas como verdes, orientando novos processos produtivos e aumentado a oferta de produtos verdes.

O projeto também proporciona a promoção de uma transparência e controle social quanto à questão, pela disponibilização dos dados no sítio do CCE-USP. Assim, a sociedade tem acesso ao descritivo das melhores práticas relacionadas ao lixo eletrônico (desde a aquisição até o descarte) e nomes das empresas e escopo de atuação na cadeia de reciclagem. Este conhecimento permite o desenvolvimento de parcerias com outras entidades do setor público, social ou privado e o fomento do envolvimento e participação de outros agentes.

Como fator crítico ao sucesso de implantação e continuação do projeto foram identificados: a conscientização da comunidade USP (funcionários, docentes e discentes); e a necessidade de haver o envolvimento dos funcionários na liderança de execução. Por isso, o CCE-USP criou uma Comissão de Sustentabilidade com a participação de pelo menos um ou dois funcionários de cada divisão. Deu-se preferência a funcionários que já tinham alguma participação anterior em projetos semelhantes ou com alguma formação e especialização em ecologia e, ainda, que manifestaram interesse pelo assunto.

Por fim, o CCE-USP vêm sendo coroado com este projeto, pelo êxito no solucionamento das dificuldades encontradas e aferição positiva na relação custo-benefício, visto que os recursos humanos participantes são provenientes de realocação (e não de novas contratações) e os recursos materiais se configuram em investimentos (contabilizados como projeto de pesquisa, de natureza não tangível). Acredita-se ainda que a venda do lixo eletrônico possa gerar recursos suficientes para tornar o projeto auto-sustentável. Quando, então, da realização de tais expectativas, o projeto atingirá seu intuito maior - a expansão de suas benesses à cadeia de regulação e consumo dos resíduos eletrônicos.

\section{OS RESÍDUOS ELETRÔNICOS DE INFORMÁTICA NAS INSTITUIÇÕES DE ENSIONO SUPERIOR DE NATAL}

O levantamento das informações acerca dos resíduos eletrônicos (e sua gestão) foi restringido aos equipamentos de informática e foi realizado em três instituições, sendo duas Universidades (uma pública e outra particular) e uma Faculdade Particular. Por motivo de resguardo, as instituições mesmas serão referidas por Instituição 1, 2 e 3, estando a numeração coerente com ordem supracitada.

Em se analisando o fluxograma do processo gerencial dos resíduos, notou-se uma semelhança na maior parte do processo para as três Instituições, havendo diferenças somente quanto à destinação final (Figura 1). Percebe-se que a única atitude de gestão dos resíduos é o reaproveitamento, os quais acontecem por motivos financeiros em todas as Instituições. 


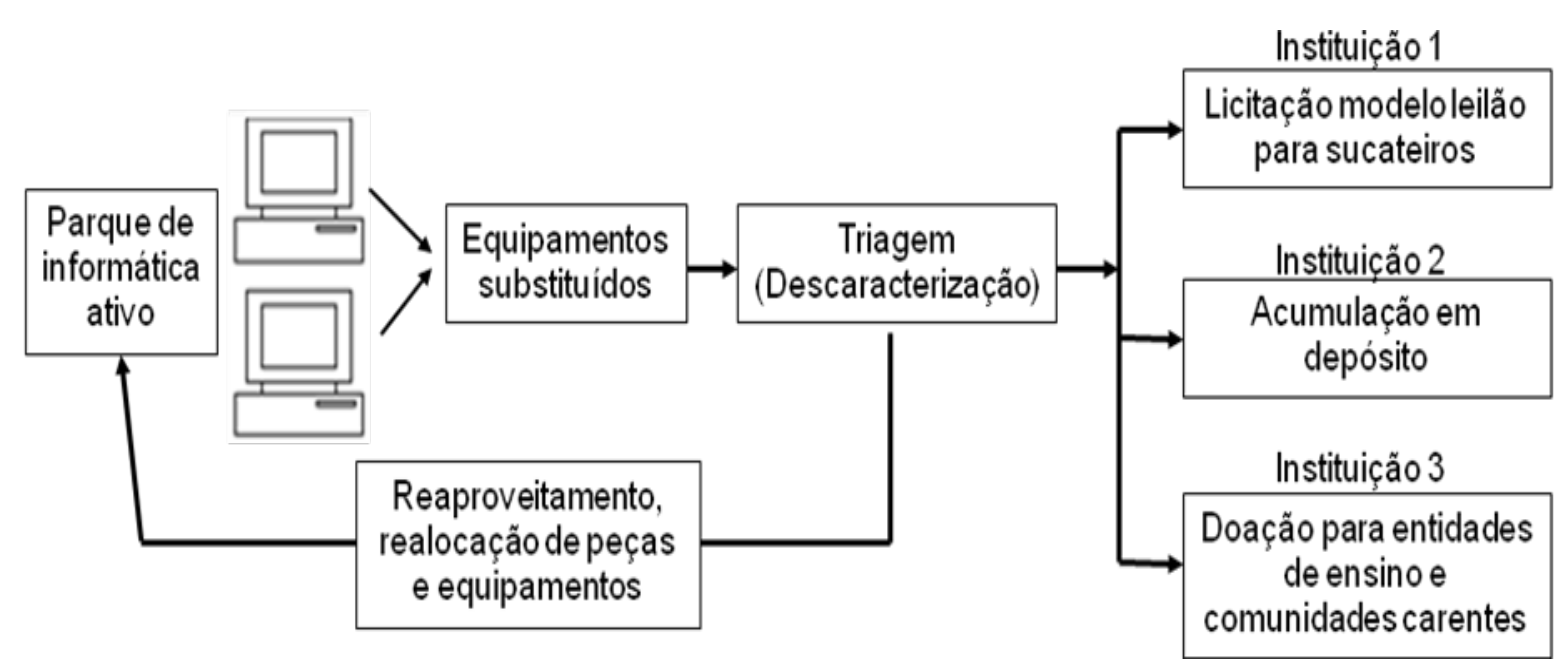

Figura 1 - Fluxograma de gestão dos Resíduos Eletrônicos de Informática nas instituições pesquisadas

De início, o próprio diagnóstico já demonstra quão incipiente ainda é a gestão dos resíduos eletrônicos pelas Instituições. A Instituição 2 não possui quaisquer contabilizações ou planos de inventariar a quantidade de equipamentos existentes em seu parque de informática ou substituídos e descartados.

Já a Instituição 1 promove uma contabilização deficitária, somente ao fim do processo, quando da triagem e destinação destes a leilão - não há quantificação dos equipamentos (componentes) retornados ao parque de informática após triagem. Os dados disponibilizados pela Instituição foram os de monitores, impressoras e microcomputadores para os exercícios de 2007 a 2009 (Tabela 2). Convém salientar que, após a triagem, as peças e equipamentos rejeitados (resíduos) raramente encontram-se completos, sendo, na prática, descaracterizadas como equipamento que possua todos seus componentes internos devidos. Disso resulta a impossibilidade de quantificação precisa de materiais descartados (plásticos, metais, etc) apenas pela porcentagem destes no equipamento quando de sua fabricação, conforme apresentado na Tabela 1.

Tabela 2 - Resíduos eletrônicos de informática da Instituição 1, de 2007 a 2009.

\begin{tabular}{lllll} 
Resíduos & $\mathbf{2 0 0 7}$ & $\mathbf{2 0 0 8}$ & $\mathbf{2 0 0 9}$ & Total \\
Monitor & 83 & 134 & 47 & $\mathbf{2 6 4}$ \\
\hline Impressoras & 72 & 80 & 17 & $\mathbf{1 6 9}$ \\
Microcomputador & 83 & 135 & 61 & $\mathbf{2 7 9}$ \\
Total & & & & $\mathbf{7 1 2}$
\end{tabular}

A Instituição 3 foi a que apresentou melhor inventário de seu parque de informática, porém apenas momentâneo. A Instituição conta atualmente com um parque de 312 microcomputadores, sendo 258 em laboratórios da rede acadêmica (substituídos a cada 2 
anos) e 54 na área administrativa (trocados a cada 4 anos). Segundo informou, a cada substituição, cerca de 50 a $60 \%$ do material é reestruturado e aproveitado como peças de reposição. O restante é doado para entidades de ensino ou comunidades carentes. Os demais equipamentos (impressoras e copiadoras) são adquiridos em regime de comodato com empresas afins e devolvidas ao fim da vida útil.

Quanto ao passo final do processo de gestão dos resíduos idealizado, algumas considerações há que se fazer. Em uma análise estritamente objetiva, infelizmente em nenhumas das três diferentes destinações, se concretiza um correto procedimento. As destinações dadas pelas Instituições 1 e 3 se configuram apenas como um repasse do problema de descarte, com os agravantes de alimentar o mercado cinza de resíduos eletrônicos (Instituição 1) e doar equipamentos em sua maioria obsoletos, inoperantes e/ou descaracterizados e, portanto, com defeitos de funcionamento (Instituição 2). A Instituição 3 , por não fazer destinação dos resíduos, permanece o problema da estocagem desses materiais, agravado pelo contínuo incremento do montante ao longo do tempo.

Feitas estas análises, devem ser ponderadas justificativas que contemplem a não existência de políticas públicas referentes à questão ou empresas recicladoras destes materiais e também, possivelmente, a carência de recursos para investimento em políticas internas (no caso da Universidade pública). Contudo, no contexto atual de ser cada vez mais corrente e pertinente a discussão acerca da sustentabilidade das atividades humanas e o papel da sociedade, das empresas privadas e das organizações públicas na implantação e adoção de ações e práticas sustentáveis, as Universidades devem ser os grandes pólos geradores e distribuidores de conhecimentos científicos que possam criar as soluções devidas à fiel execução sustentável dos processos produtivos. À luz desta ótica e exemplo dado pela USP é que as Instituições podem buscar os meios necessários a consecução da devida gestão dos resíduos eletrônicos.

\section{DISCUSSÕES E CONSIDERAÇÕES FINAIS}

O conteúdo exposto corrobora com a problemática atual em relação à ineficiente (ou mesmo inexistente) gestão dos resíduos eletrônicos de informática. Em razão da carência por conscientização e ausência de legislação de responsabilização dos produtores e usuários de bens de informática e eletrônicos, não se observa uma preocupação real quanto aos danos (econômicos, sociais, ambientais) causados e nem quanto à imagem da instituição.

Percebe-se que o reaproveitamento de equipamentos, quando da triagem e reestruturação dos mesmos, é feito apenas por motivos econômicos. Isto é posto por duas razões. Primeiramente porque não há sequer um acompanhamento conciso em valores de quanto é recuperado e quanto de lixo eletrônico é produzido. Além disso, é totalmente inexistente qualquer processo de reciclagem. Em suma, nenhuma das formas de destinação observadas foram consideradas corretas, visto à inação ou transferência dos resíduos (e consequentemente da responsabilidade) para outros atores da cadeia sem garantias de um correto ou real aproveitamento ou tratamento. Refletindo um aspecto sócio-cultural nacional (e global) majoritário acerca da questão, não existe o concernimento acerca da 
logística reversa desses equipamentos enquanto resíduos. A doação dos equipamentos (muitas vezes já na condição de resíduos pelo mau ou não funcionamento) não garante um destino final sustentável para estes bens, assim como o leiloamento dos equipamentos, que reflete o tratamento destes como mera sucata.

Tais formas de gestão (em termos principalmente da destinação), comuns a grande maioria dos setores da sociedade, inviabilizam o mapeamento do ciclo de vida de um computador. Disto resulta que o conhecimento sobre o prolongamento da vida útil destes equipamentos é mais intuitivo do que baseado em números e dados reais, dificultando a visualização do problema em termos práticos e, por consequência, o delineamento de ações corretivas.

Acredita-se que a questão dos resíduos eletrônicos merece a devida atenção das instituições pela sua amplitude e necessidade (dever) das mesmas em serem exemplos, enquanto entidades de ensino superior, quanto à prática do desenvolvimento e sustentabilidade. $\mathrm{O}$ projeto 'Criação de Cadeia de Transformação de Lixo Eletrônico', entabulado pelo CCEUSP, serve como boa base ao início da consecução deste sensato objetivo.

\section{REFERÊNCIAS}

1. ADRIANO SILVA, Lorena Albuquerque et al. Lixo eletrônico e as perspectivas de uma sociedade de consumo: um estudo exploratório na cidade de Natal-RN. I Jornada Científica de Ferramentas de Gestão Ambiental para Competitividade e Sustentabilidade - JCGA 2009. Natal-RN. 2009. 9p.

2. AMBIENTE BRASIL. Metais Pesados. Disponível em: $<$ http://www.ambientebrasil.com.br/composer.php3?base=residuos/index.php3\&cont eudo=./residuos/artigos/metais.html>. Acesso em: 01 Nov 2009.

3. ANTUNES, Fernando. Brasil atingirá 170 milhões de celulares em 2009, aponta estudo. Folha Online: 14 Ago2008. Disponível em: <http://www1.folha.uol.com.br/folha/dinheiro/ult91u433522.shtml>. Acesso em: 22 Out 2009.

4. BRASIL. Resolução CONAMA n²57, de 30 de junho de 1999. Diário Oficial da União Federativa do Brasil, Poder Executivo, Brasília, DF, 22 set. 1999.

5. BAN, Basel Action Network. Disponível em: <http://www.ban.org>. Acesso em: 14 Nov 2009.

6. CARVAlHO, Tereza Cristina M. B.; et al. Projeto de Criação de Cadeia de Transformação de Lixo Eletrônico da Universidade de São Paul. Prêmio Mário Covas, USP: São Paulo - SP. 2008. 15p.

7. CELERE. Marina S. et al. Metais presentes no chorume coletado no aterro sanitário de Ribeirão Preto, São Paulo, Brasil, e sua relevância para saúde pública. Cadernos de Saúde Pública, vol. 23, nº 4, Rio de Janeiro, Abril, 2007

8. DEUTSCHE WELLE BRASIL. União Européia discute o lixo eletrônico. 2004. Disponível em: <http://www.reciclaveis.com.br/noticias/.htm>. Acesso em: 03 Nov 2009. 
9. DOYLE, Alister. Nova aliança para combater as montanhas de lixo eletrônico. Reuters, $2007 . \quad$ Disponível em: $<$ http://br.hsmglobal.com/canais/notic.php?marcabusca=reciclagem>. Acesso em: 17 Out 2009.

10. ENVIRONMENT AGENCY. Waste electrical and electronic equipment (WEEE). Disponível em: <http://www.environmentagency.gov.uk/business/topics/waste/32084.aspx >. Acesso em: 17 Nov 2009.

11. ESTRADA, Daniela. O segredo do modelo nórdico: Os riscos do lixo eletrônico. Terramérica, 202 Jan 2005.2 Disponível em $<$ http://www.mwglobal.org/ipsbrasil.net/nota.php?idnews=25>. Acesso em: 02.Nov 2009.

12. GREENPEACE. Metais pesados: contaminando a vida. Disponível em: $<$ http://www.greenpeace.org.br/toxicos/?conteudo_id=818\&sub_campanha=0\&img= 15>. Acesso em: 15 Out 2009.

13. LEITE, Paulo Roberto; LAVEZ, Natalie; SOUZA, Vivian Mansano. Fatores da logística reversa que influem o reaproveitamento do "lixo eletrônico" - Um estudo no setor de informática. XII Simpósio de Administração da Produção, Logística e Operações Internacionais - SIMPOI 2009. São Paulo - SP. 2009. 16p.

14. MCC, Microelectronics and Computer Technology Corporation. Electronics Industry Environmental Roadmap. Austin, TX: MCC, 2007.

15. MEIRELLES, F. S. Pesquisa Anual CIA. FGV-EAESP, 19a edição, 2008.

16. PORTAL da câmara dos Deputados. Política Nacional dos Resíduos Sólidos. Disponível

em:

<http://www2.camara.gov.br/internet/proposicoes/chamadaExterna.html?lin>. Acesso em: 16 Nov 2009.

17. SILVA, Bruna Daniela; OLIVEIRA, Flávia Cremonesi; MARTINS, Dalton Lopes. Resíduos Eletroeletrônicos no Brasil, Santo André, 2007. 59 p.

18. SOMMER, Mark. O lado obscuro do lixo eletrônico. Tierramérica: 2005. Disponível em: < http://www.tierramerica.net/2005/0402/pgrandesplumas.shmtl>. Acesso em: 27 Out 2009.

19. STEP. StEP - Solving the e-Waste Problem. Disponível em: < http://www.stepinitiative.org/>. Acesso em: 18 Nov 2009. 